\title{
Postoperative spinal orthosis may not be necessary for minimally invasive lumbar spine fusion surgery: a prospective randomized controlled trial
}

\author{
Hsuan-Hsiao Ma ${ }^{1,2}$, Pei-Hsi Wu ${ }^{1,2}$, Yu-Cheng Yao ${ }^{1,2}$, Po-Hsin Chou ${ }^{1,2}$, Hsi-Hsien Lin ${ }^{1,2^{*}}$, Shih-Tien Wang ${ }^{1,2}$ and \\ Ming-Chau Chang ${ }^{1,2}$
}

\begin{abstract}
Background: With the progress and success in minimally invasive surgery of transforaminal lumbar interbody fusion (MIS TLIF), the musculoskeletal injury was minimized. However, the role of postoperative orthosis in MIS TLIF has not been established and there is little evidence supporting the routine use of orthosis in MIS TLIF.

Methods: This is a prospective randomized clinical study. 90 patients who underwent MIS TLIF were randomly divided into groups A (with postoperative spinal orthosis) and B (without postoperative spinal orthosis). Patients were followed up for an average of 12.6 months. Clinical outcome was assessed using the Oswestry disability index (ODI) and visual analogue scale (VAS). Fusion rate was classified with the BSF scale system at postoperative 6-month, and 12-month.

Results: Both groups had similar patient demographics. The use of postoperative spinal orthosis had no significant influence on instrumentation-related complications or radiological parameters at each follow-up.
\end{abstract}

Conclusions: In this study, we conclude that postoperative spinal orthosis is not necessary for MIS TLIF. Patients without postoperative spinal orthosis had the same fusion rates and improvement of VAS and ODI scores.

Keywords: Brace, Clinical Outcome, Minimally invasive surgery, Radiographic solid fusion, Lumbar spinal orthosis, TLIF

\section{Background}

Lumbar orthoses are used extensively in various conditions including low back pain [1], spondylolisthesis, spinal deformity, and during the postoperative period [2]. However, the necessity of rigid bracing after lumbar fusions has been questioned. In general, immobilization of any musculoskeletal injury will help in the relief of the

*Correspondence: hhl.vghtpe@gmail.com

${ }^{1}$ Department, of Orthopedics and Traumatology, Taipei Veterans General Hospital, No. 201, Section. 2, Shi-pai Road, Taipei 11217, Taiwan, ROC

Full list of author information is available at the end of the article pain secondary to the injury [3]. And the goals of postoperative orthosis include immobilizing gross body motion [4] and motion segments, unloading the force [5], reducing pain [6], enhancing the fusion rate [7], and improving functional outcomes [8].

The effect of restricting gross motions of the trunk rather than intervertebral mobility by orthosis in the lumbar spine was confirmed using roentgen stereophotogrammetric analysis [9]. Besides, the functional outcomes were found not improved by postoperative bracing in posterior [10] and posterolateral spinal instrumented fusion [11]. Moreover, the drawbacks of postoperative 
orthosis include muscle atrophy [12], skin irritation, additional costs, and delays in rehabilitation.

With the progress and success in minimally invasive surgery of transforaminal lumbar interbody fusion (MIS TLIF), the musculoskeletal injury was minimized with significant reductions of operative time, length of stay, VAS scores compared with the open technique [13]. However, the role of postoperative orthosis in MIS TLIF has not been established and there is little evidence supporting the routine use of orthosis in MIS TLIF. Thus, we performed a prospective randomized trial to evaluate the necessity of a postoperative external lumbar orthosis as an adjunct therapy for patients treated with MIS TLIF for degenerative conditions.

\section{Methods}

Between November 2016 and April 2017, 90 patients who underwent MIS TLIF in our institute were enrolled prospectively after institutional review board approval (2015-08-006ACF) and the protocol has been registered in ClinicalTrials.gov. Indications for surgery were grade 1 spondylolisthesis, pars fractures, and degenerative discs with back pain or radiculopathy that involves only one or two segments. The surgical level ranges from the second lumbar vertebra (L2) to the first sacral vertebra (S1). All surgeries were performed by a single surgeon. Patients with spinal fracture, spinal infection, intraspinal tumor, previous spine surgery, osteoporosis $(\mathrm{T}<-2.5)$, systemic autoimmune disease, end-stage renal disease, and Parkinsonism were excluded.

\section{Surgical technique}

Under general anesthesia, patient was placed in prone position on the four-poster frame. Intraoperative 3-dimensional C-arm (Vision FD Vario 3D, Ziehm Imaging, Nuremberg, Germany) and navigation system (Kick navigation system, Brainlab) were used for percutaneous pedicle screw insertions. Intraoperative scanning was performed in both groups with CT data set automatically registered to the image guidance system. Before the $1.5-\mathrm{cm}$ skin incision was made, the spinal process was used as an anatomical landmark by navigation probe to confirm the accuracy of navigation. The ideal skin entry points were sought with the navigation probe tip in order to determine the precise skin incision based on the virtual elongated navigation trajectory on the intraoperative scanned images. Pedicle entry points were decided on navigation guidance, and pilot holes were made with a 3-mm awl. The direction of the pilot pedicle hole was rechecked with the navigation probe, and 4.5-mm tapping was done to a depth of $20 \mathrm{~mm}$ from the entry point. A guidewire was used for screw insertion. The size of the pedicle screws was determined under the navigation system. Rod was then placed and fixed with nuts after rechecking the position. Microscopic decompression and transforaminal lumbar interbody fusion was then performed under the incision for pedicle screws with cage, demineralized bone matrix(OsteoSelect AQ3 DBM Putty, Bacterin International Inc., Belgrade, MT), and autologous bone graft $[14,15]$. All surgeries were performed by 1 senior spinal surgeon.

\section{Postoperative care}

They were randomly distributed to either group A or group B using computer-generated random numbers. Patients in group A undergone MIS TLIF were protected with postoperative spinal orthosis for 3 months. A rigid chairback brace (Fig. 1) was used full-time after ambulation except bathing and lying on bed. Patients in group B did not use any rigid brace or lumbar corset. The allocation was shown in the consort-diagram (Fig. 2).

\section{Clinical evaluation and functional assessment}

Patients were followed at postoperative 1-month, 3-month, 6-month, and 12-month. Radiographs included anteroposterior, lateral lumbar spine views, and lateral standing flexion-extension views. The success of interbody fusion was evaluated by computed tomography (CT) at the 6-month and 12-month postoperative followup using the Brantigan-Steffee-Fraser (BSF) classification.

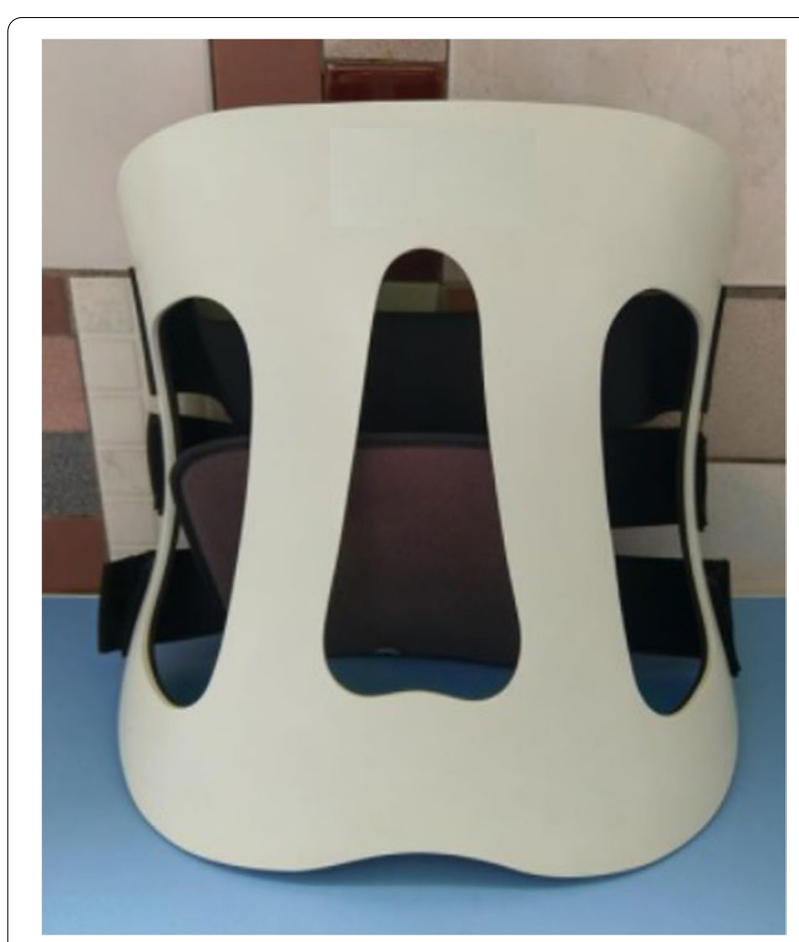

Fig. 1 The Rigid chairback brace used in this study 


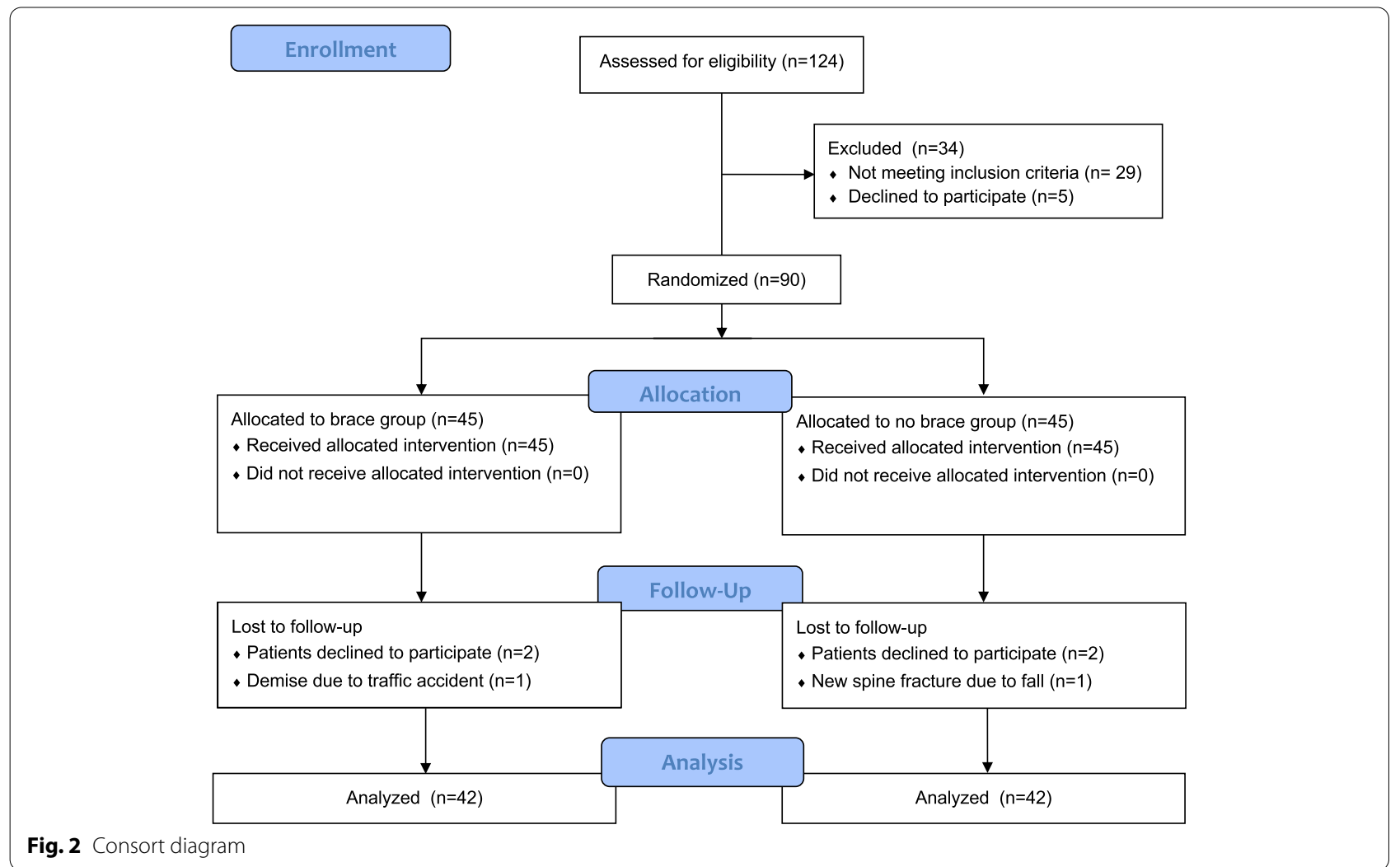

An additional computed tomography (CT) scan was done in cases of uncertainty of screw position or in in case of symptomatic patients during the follow up. Clinical and radiographic assessments were performed by an independent blinded observer not involved in patient care. As seen radiographically, fusion was graded by BSF classification (Fig. 3).

Perioperative parameters were recorded including surgical duration, timing of ambulation, length of hospital stay and complications. All patients were regularly followed up at our clinics. There were 1 patient in each group had accidental falling and were excluded. None of the patients dropped out of the study due to unknown reasons. Clinical outcomes were assessed using the Oswestry disability index (ODI) and visual analogue scale (VAS) preoperatively, at 1-, 3-, 6-, and 12-month postoperatively.

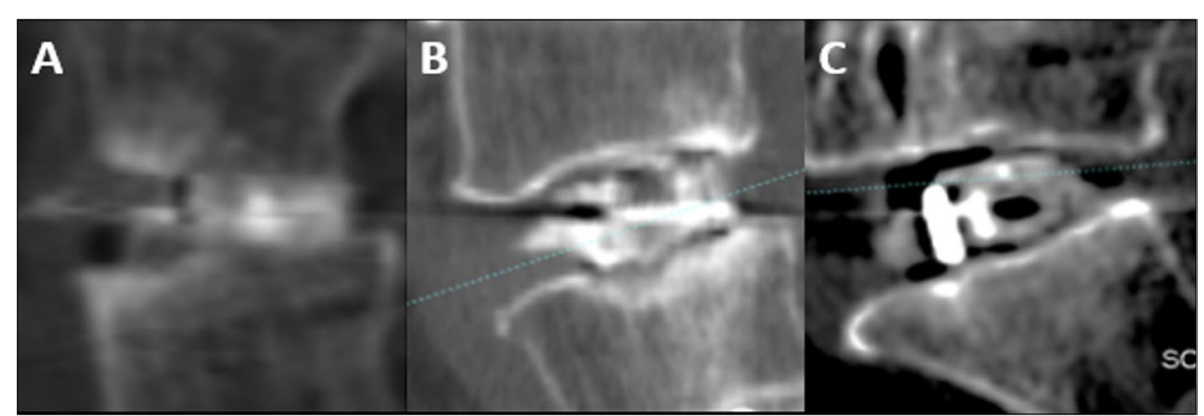

Fig. 3 A BSF-3, fusion with remodeling and trabecular present. B BSF-2, graft intact, not fully remodeled and incorporated, but no lucency present. C BSF-1, graft intact but with lucency visible around the graft or cage 


\section{Statistical analysis}

To determine the ideal sample size required to achieve an alpha level of 0.05 with $90 \%$ power, we assumed noninferiority of "without brace" compared with "with brace" if the mean difference of the ODI score across interventions was less than one-third of minimal clinical important difference (MCID). The MCID of the ODI based on the previous study was 14.9 points and the estimated standard deviation of $11.3[16,17]$. Assuming a $20 \%$ loss to followup, a final ideal sample size of at least 30 patients in each group was determined.

The patients' age, body mass index (BMI), preoperative VAS, preoperative ODI, operative time, timing of ambulation and length of stay were analysed with independent sample $t$ test. The clinical outcomes (VAS and ODI) of each group after operation were analysed using paired $t$ test. Categorical data were compared using the $\chi^{2}$ or the Fisher exact test. Differences in sex, medical history and complications between groups were assessed using Mann-Whitney Test. Statistical significance was set at $p<0.05$. All statistical analyses were performed using SPSS version 20 (IBM, Chicago, IL, USA).

\section{Results}

The mean age of the patients was $69.1 \pm 9.1$ years (range, $48-78$ years) in group A and $70.8 \pm 8.9$ years (range, 56-85 years) group B. The mean BMI of the patients was $26.2 \mathrm{~kg} / \mathrm{m}^{2}$ in group $A$ and $26.1 \mathrm{~kg} / \mathrm{m}^{2}$ in group $B$. In group $\mathrm{A}, 30$ and 12 patients underwent one- and two-level surgery, respectively, whereas in group B, 30 and 12 patients underwent one- and two-level surgery, respectively.

In group A, 6 patients had diabetes mellitus and 7 patients were smokers. In group B, 12 patients had diabetes mellitus, and 2 patients were smokers. Age, sex, BMI, levels of surgery, underlying medical condition (diabetes mellitus and smoking) showed no significant difference between the two groups (Table 1).

The preoperative VAS is $5.9 \pm 1.4$ in group $\mathrm{A}$ and $5.6 \pm 0.8$ in group $\mathrm{B}$, and the preoperative ODI is $51.0 \pm 13.9$ in group A and $48.3 \pm 10.6$ in group B. There were no significant differences in preoperative VAS $(p=0.181)$ and ODI $(p=0.469)$ between the two groups (Table 1 ). The mean operative time was $3.9 \mathrm{~h}$ in group $\mathrm{A}$, and $4.2 \mathrm{~h}$ in group $\mathrm{B}$. There was no significant difference between each group $(p=0.480)$. The timing of ambulation is 2.2 days in group $\mathrm{A}$ and 2.0 days in group $\mathrm{B}$. The length of hospitalization is 7.0 days in group $\mathrm{A}$ and 6.9 days in group $\mathrm{B}(p=0.588)$ (Table 2$)$.

The VAS score at 1 month was $1.4 \pm 1.30$ in group $A$ and $1.3 \pm 0.97$ in group $B$, and the VAS scores at 12 months were $1.2 \pm 1.46$ in group $\mathrm{A}$ and $1.1 \pm 1.18$ in group $B$. The ODI score at 1 month was $18.0 \pm 4.42$ in
Table 1 Patient demographics

\begin{tabular}{|c|c|c|c|}
\hline & Group A $(n=42)$ & Group B $(n=42)$ & $p$-value \\
\hline Age (years, mean \pm SD) & $69.1 \pm 9.1$ & $70.8 \pm 8.9$ & 0.645 \\
\hline Sex (female, \%) & $34(81.0 \%)$ & $30(71.4 \%)$ & 0.443 \\
\hline $\begin{array}{c}\mathrm{BMI}\left(\mathrm{kg} / \mathrm{m}^{2}\right. \\
\text { mean } \pm \mathrm{SD})\end{array}$ & $26.2 \pm 3.2$ & $26.1 \pm 3.6$ & 0.985 \\
\hline $\begin{array}{c}\text { DEXA (T-score, } \\
\text { mean } \pm S D)\end{array}$ & $-1.0 \pm 1.52$ & $-1.1 \pm 1.18$ & 0.780 \\
\hline $\begin{array}{l}\text { Spinal level, fused } \\
\qquad(\mathrm{n}, \%)\end{array}$ & & & 0.715 \\
\hline$L 2-3$ & $0(0)$ & $2(4.8)$ & \\
\hline L3-4 & $2(4.8)$ & $3(7.1)$ & \\
\hline L3-L5 & $6(14.3)$ & $7(16.7)$ & \\
\hline$\llcorner 4-5$ & $26(61.9)$ & $22(52.4)$ & \\
\hline L4-S1 & $6(14.3)$ & $5(11.9)$ & \\
\hline L5-S1 & $2(4.8)$ & $3(7.1)$ & \\
\hline \multicolumn{4}{|l|}{ Medical history (n, \%) } \\
\hline $\mathrm{DM}$ & $6(14.2)$ & $12(28.6)$ & 0.183 \\
\hline Smoking & $7(16.7)$ & $2(4.8)$ & 0.156 \\
\hline
\end{tabular}

$B M I$ body mass index, DM diabetes mellitus

group $\mathrm{A}$ and $18.8 \pm 10.11$ in group $\mathrm{B}$, whereas the ODI scores at 12 months were $8.6 \pm 4.90$ in group $A$ and $8.2 \pm 5.63$ in group B. VAS and ODI scores significantly improved after surgery in both groups. The amplitude of VAS and ODI improvement was similar at each followup between both groups.

For the purposes of statistical analysis, BSF-2 and BSF-3 on CT scans were regarded as successful fusion, and BSF-1 was regarded as non-union. In the entire cohort, there was no BSF-1 in each group. The fusion rates at 6-month and 12-month follow-up showed no significant between the groups (Table 3 ).

In terms of complications, there were one superficial wound infection and one pedicle screw loosening in group A and one early postoperative pulmonary embolism in group B which totally recovered after medical treatment. Overall, complications occurred in 4.8 and $2.4 \%$ of the patients in the control and experimental group respectively (Table 4 ).

\section{Discussion}

Historically, the use of a spinal orthosis after open lumbar fusion surgery is generally adopted. However, earlier studies revealed insufficient evidence that lumbar supports are more effective than no treatment [8]. And there is an obvious lack of consensus regarding the most appropriate type, duration, and indications for immobilization that support the routine use of postoperative lumbar supports after spinal surgeries [18]. For thoracolumbar fractures, treatment using early ambulation without a brace avoids the cost and patient 
Table 2 Perioperative and clinical outcomes

\begin{tabular}{|c|c|c|c|}
\hline & Group A $(n=42)$ & Group B $(n=42)$ & $p$ \\
\hline Operative time (hours, mean \pm SD)) & $3.9 \pm 1.02$ & $4.2 \pm 1.05$ & 0.480 \\
\hline Timing of ambulation (days, (mean $\pm S D$ ) & $2.2 \pm 1.22$ & $2.0 \pm 1.12$ & 0.220 \\
\hline Length of stay (days, (mean \pm SD) & $7.0 \pm 2.23$ & $6.9 \pm 1.98$ & 0.588 \\
\hline \multicolumn{4}{|l|}{ VAS (mean $\pm S D)$} \\
\hline Preoperative & $5.9 \pm 1.4$ & $5.6 \pm 0.8$ & 0.181 \\
\hline Postoperative 1 months & $1.4 \pm 1.30$ & $1.3 \pm 0.97$ & 0.923 \\
\hline Postoperative 3 months & $1.30 \pm 1.13$ & $1.2 \pm 0.96$ & 0.823 \\
\hline Postoperative 6 months & $1.4 \pm 1.12$ & $1.1 \pm 0.57$ & 0.259 \\
\hline Postoperative 12 months & $1.2 \pm 1.46$ & $1.1 \pm 1.18$ & 0.882 \\
\hline \multicolumn{4}{|l|}{$\mathrm{ODI}($ mean $\pm \mathrm{SD})$} \\
\hline Preoperative & $51.0 \pm 13.9$ & $48.3 \pm 10.6$ & 0.469 \\
\hline Postoperative 1 month & $18.0 \pm 4.42$ & $18.8 \pm 10.11$ & 0.764 \\
\hline Postoperative 3 months & $14.0 \pm 9.40$ & $13.2 \pm 6.16$ & 0.777 \\
\hline Postoperative 6 months & $10.3 \pm 4.96$ & $10.2 \pm 5.35$ & 0.982 \\
\hline Postoperative 12 months & $8.6 \pm 4.90$ & $8.2 \pm 5.63$ & 0.898 \\
\hline
\end{tabular}

VAS Visual Analogue Scale, ODI Oswestry disability index

Table 3 Fusion rate between two groups

\begin{tabular}{llll}
\hline & Group A $(\boldsymbol{n}=\mathbf{4 2})$ & Group B $(\boldsymbol{n}=\mathbf{4 2})$ & P value \\
\hline $\begin{array}{llll}\text { BSF classification } \\
\text { by CT scan (n, \%) }\end{array}$ & & & 1.000 \\
BSF-1 & $0(0 \%)$ & $0(0 \%)$ & \\
BSF-2 & $3(7.1 \%)$ & $2(4.8 \%)$ & \\
BSF-3 & $39(92.9 \%)$ & $40(95.2 \%)$ & \\
Fusion rate (\%) & & & 0.928 \\
6-month & $83 \%$ & $81 \%$ & \\
12-month & $100 \%$ & $100.0 \%$ & \\
\hline
\end{tabular}

BSF Brantigan-Steffee-Fraser

Table 4 Complications and reoperations

\begin{tabular}{llll}
\hline & $\begin{array}{l}\text { Group A } \\
(\mathbf{N = 4 2 )}\end{array}$ & $\begin{array}{l}\text { Group B } \\
(\mathbf{N = 4 2 )}\end{array}$ & $\begin{array}{l}\boldsymbol{P} \text { value } \\
\text { Complications }\end{array}$ \\
$\begin{array}{l}\text { Perioperative complications } \\
\text { Superficial wound infection }\end{array}$ & 1 & 0 & - \\
$\quad$ Epidural hematoma & 0 & 0 & - \\
$\quad$ Nerve root damage & 0 & 0 & - \\
$\quad$ Implants dislodge & 0 & 0 & - \\
Medical-related complications & & & - \\
$\quad$ Pulmonary embolism & 0 & 1 & - \\
Implants-related complications & & & - \\
$\quad$ Screw loosening & 1 & 0 & - \\
$\quad$ Screw broken & 0 & 0 & - \\
$\quad$ Cage migration & 0 & 0 & - \\
Total (n) & 2 & 1 & 1.000 \\
Reoperation due to complications & 0 & 0 & - \\
\hline
\end{tabular}

All data were expressed as number of patients deconditioning associated with a brace [19], and the Oswestry Disability Index scores for the treatment of compression fractures without a brace were not inferior to those with soft or rigid braces [20].

For lumbar spine fusion surgery, the benefits of using postoperative brace are controversial. There was no significant impact on the risk of non-union following cervical or lumbar fusions [21]. Despite no negative effect by the continuous use of a lumbosacral orthosis for 1-6 months, there might be the influence of duration of postoperative lumbar immobilization with the aid of a rigid lumbar orthosis on the consolidation of posterolateral lumbosacral fusions [22]. However, the quality of evidence ranged from low to very low in one meta-analyses study [23]. And the routine use of bracing following instrumented posterolateral fusion is not recommended [24].

The MIS technique preserves the posterior tension band, and the back muscle groups were minimally detached. However, transforaminal technique always includes unilateral or bilateral facetectomy [25], and removal of the intervertebral disc, which may cause greater instability than performing posterolateral fusion. In our study, all patients received unilateral facetectomy, and there was no significant difference in fusion assessment between two groups at 3-month, 6-month, and 12-month follow-up. Although a CT scan may show a high sensitivity for pseudarthrosis compared with plain film, plain X-ray films and helical CT scans showed equal accuracy after posterior lumbar interbody fusion confirmed by surgical exploration [26]. 
Patients might feel more comfortable and it might be more convenient for earlier postoperative rehabilitation without a postoperative spinal orthosis. We designed this study to assess the bracing effect on patient-derived functional outcomes. In our experience, patients feel discomfort when putting-on or taking-off the brace, which may make them hesitate from starting mobilization.

This study has some limitations. Osteoporotic patients were excluded as non-union and cage subsidence are well-known complications in osteoporotic patients who undergo lumbar interbody fusion surgery [27]. Minor subsidence might be due to end-plate manipulation during cage insertion and was not included in the complications in this study. Future studies of postoperative bracing in osteoporotic patients may be needed. Second, the fusion rate at 12-month seems to be too high and postoperative ODI seems to be lower in both groups. The reasons might include small sample size with the same experienced surgical technique, routine DBM use, and cultural response in Taiwan. Third, minor complications, such as durotomy, urinary tract infection, and persistent neurological paresthesia were not reported in this study. Forth, brace compliance in clinical scenario lacks a reliable and objective measure since clear instructions about brace wear were given.

To our best knowledge, this study is the first prospective randomized trial to evaluate the outcomes both functionally and radiographically following minimally invasive transforaminal lumbar interbody fusion for degenerative conditions. We believed that not using a postoperative orthosis would achieve a more comfortable postoperative period, easier recovery and higher patient satisfaction.

\section{Conclusion}

The necessity of routinely used postoperative spinal orthosis in lumbar spine surgery has been questioned. Previous studies found no benefits in the use of orthosis in reducing pain or preventing non-union. In this study, we found that postoperative spinal orthosis does not improve outcomes in MIS TLIF. Patients without postoperative spinal orthosis had the same fusion rates and improvement of VAS and ODI scores.

\section{Acknowledgements}

Not applicable.

\begin{abstract}
Authors' contributions
Concept, literature search and data collection: H-HM, H-HL, Y-CY. Statistics, data analysis and interpretation: $\mathrm{H}-\mathrm{HM}, \mathrm{H}-\mathrm{HL}, \mathrm{M}-\mathrm{CC}$. Drafting article: $\mathrm{H}-\mathrm{HM}$, S-TW. Critical revision of article: P-HC. All authors have read and approved the manuscript.
\end{abstract}

\section{Funding}

This study received no funding
Availability of data and materials

The information to access the data used in the study is included within this article.

\section{Declarations}

Ethics approval and consent to participate

The medical ethics committee of Taipei Veterans General Hospital approved the study (2015-08-006ACF). Written informed consent were obtained from all the participants. All procedures were performed in accordance with relevant guidelines.

\section{Consent for publication}

Not applicable.

\section{Competing interests}

The authors declare that they have no competing interests.

\section{Author details}

${ }^{1}$ Department, of Orthopedics and Traumatology, Taipei Veterans General Hospital, No. 201, Section. 2, Shi-pai Road, Taipei 11217, Taiwan, ROC. ${ }^{2}$ School, of Medicine, National Yang Ming Chiao Tung University University, Taipei City, Taiwan, ROC.

Received: 27 March 2021 Accepted: 22 June 2021

Published online: 12 July 2021

\section{References}

1. Morrisette DC, Cholewicki J, Logan S, Seif G, McGowan S. A randomized clinical trial comparing extensible and inextensible lumbosacral orthoses and standard care alone in the management of lower back pain. Spine. 2014;39(21):1733-42.

2. Agabegi SS, Asghar FA, Herkowitz HN. Spinal orthoses. J Am Acad Orthop Surg. 2010;18(11):657-67.

3. Connolly PJ, Grob D. Bracing of patients after fusion for degenerative problems of the lumbar spine-yes or no? Spine. 1998;23(12):1426-8.

4. Lantz SA, Schultz AB. Lumbar spine orthosis wearing. I. Restriction of gross body motions. Spine. 1986;11(8):834-7.

5. Rohlmann A, Zander T, Graichen F, Bergmann G. Effect of an orthosis on the loads acting on a vertebral body replacement. Clin Biomech. 2013;28(5):490-4.

6. Spratt KF, Weinstein JN, Lehmann TR, Woody J, Sayre H. Efficacy of flexion and extension treatments incorporating braces for low-back pain patients with retrodisplacement, spondylolisthesis, or normal sagittal translation. Spine. 1993;18(13):1839-49.

7. Kim SS, Denis F, Lonstein JE, Winter RB. Factors affecting fusion rate in adult spondylolisthesis. Spine. 1990;15(9):979-84.

8. Jellema P, van Tulder MW, van Poppel MN, Nachemson AL, Bouter LM. Lumbar supports for prevention and treatment of low back pain: a systematic review within the framework of the Cochrane Back Review Group. Spine. 2001;26(4):377-86.

9. Axelsson $\mathrm{P}$, Johnsson $\mathrm{R}$, Stromqvist B. Effect of lumbar orthosis on intervertebral mobility. A roentgen stereophotogrammetric analysis. Spine. 1992;17(6):678-81.

10. Soliman HA, Barchi S, Parent S, Maurais G, Jodoin A, Mac-Thiong JM. The early impact of postoperative bracing on pain and quality of life following posterior instrumented fusion for lumbar degenerative conditions: a randomized trial. Spine. 2017;43:155-60.

11. Yee AJ, Yoo JU, Marsolais EB, Carlson G, Poe-Kochert C, Bohlman HH, Emery SE. Use of a postoperative lumbar corset after lumbar spinal arthrodesis for degenerative conditions of the spine. A prospective randomized trial. J Bone Joint Surg Am. 2008;90(10):2062-8.

12. Rostami M, Noormohammadpour P, Sadeghian AH, Mansournia MA, Kordi R. The effect of lumbar support on the ultrasound measurements of trunk muscles: a single-blinded randomized controlled trial. PM R. 2014;6(4):302-8 quiz 308.

13. Singh K, Nandyala SV, Marquez-Lara A, Fineberg SJ, Oglesby M, Pelton MA, Andersson GB, Isayeva D, Jegier BJ, Phillips FM. A perioperative cost 
analysis comparing single-level minimally invasive and open transforaminal lumbar interbody fusion. Spine J. 2014;14(8):1694-701.

14. Lin HH, Lu YH, Chou PH, Chang MC, Wang ST, Liu CL. Is bony attachment necessary for dynamic reference frame in navigation-assisted minimally invasive lumbar spine fusion surgery? Comput Assist Surg. 2019;24(1):7-12.

15. Lin HH, Chou PH, Ma HH, Chang YW, Wang ST, Chang MC. Efficacy of povidone iodine solution in the prevention of surgical site infections in minimally invasive instrumented spinal fusion surgery. Global Spine J. 2020:2192568220975385.

16. Parker SL, Adogwa O, Paul AR, Anderson WN, Aaronson O, Cheng JS, McGirt MJ. Utility of minimum clinically important difference in assessing pain, disability, and health state after transforaminal lumbar interbody fusion for degenerative lumbar spondylolisthesis. J Neurosurg Spine. 2011;14(5):598-604.

17. Parker SL, Mendenhall SK, Shau DN, Adogwa O, Anderson WN, Devin CJ, McGirt MJ. Minimum clinically important difference in pain, disability, and quality of life after neural decompression and fusion for same-level recurrent lumbar stenosis: understanding clinical versus statistical significance. J Neurosurg Spine. 2012;16(5):471-8.

18. Bible JE, Biswas D, Whang PG, Simpson AK, Rechtine GR, Grauer JN. Postoperative bracing after spine surgery for degenerative conditions: a questionnaire study. Spine J. 2009;9(4):309-16.

19. Bailey CS, Urquhart JC, Dvorak MF, Nadeau M, Boyd MC, Thomas KC, Kwon BK, Gurr KR, Bailey SI, Fisher CG. Orthosis versus no orthosis for the treatment of thoracolumbar burst fractures without neurologic injury: a multicenter prospective randomized equivalence trial. Spine J. 2014;14(11):2557-64.

20. Kim HJ, Yi JM, Cho HG, Chang BS, Lee CK, Kim JH, Yeom JS. Comparative study of the treatment outcomes of osteoporotic compression fractures without neurologic injury using a rigid brace, a soft brace, and no brace: a prospective randomized controlled non-inferiority trial. J Bone Joint Surg Am. 2014;96(23):1959-66.
21. George KJ, Fehlings MG. Is routine postoperative cervical bracing after instrumentation necessary? World Neurosurg. 2013;79(2):273-4.

22. Johnsson R, Stromqvist B, Axelsson P, Selvik G. Influence of spinal immobilization on consolidation of posterolateral lumbosacral fusion. A roentgen stereophotogrammetric and radiographic analysis. Spine. 1992;17(1):16-21.

23. Takasaki H, Miki T. The impact of continuous use of lumbosacral orthoses on trunk motor performance: a systematic review with meta-analysis. Spine J. 2017;17(6):889-900.

24. Dailey AT, Ghogawala Z, Choudhri TF, Watters WC 3rd, Resnick DK, Sharan A, Eck JC, Mummaneni PV, Wang JC, Groff MW, et al. Guideline update for the performance of fusion procedures for degenerative disease of the lumbar spine. Part 14: brace therapy as an adjunct to or substitute for lumbar fusion. J Neurosurg Spine. 2014;21(1):91-101.

25. Tye EY, Alentado VJ, Mroz TE, Orr RD, Steinmetz MP. Comparison of clinical and radiographic outcomes in patients receiving single-level transforaminal lumbar interbody fusion with removal of unilateral or bilateral facet joints. Spine. 2016;41(17):E1039-1045.

26. Fogel GR, Toohey JS, Neidre A, Brantigan JW. Fusion assessment of posterior lumbar interbody fusion using radiolucent cages: $x$-ray films and helical computed tomography scans compared with surgical exploration of fusion. Spine J. 2008;8(4):570-7.

27. Ebata S, Takahashi J, Hasegawa T, Mukaiyama K, Isogai Y, Ohba T, Shibata Y, Ojima T, Yamagata Z, Matsuyama Y, et al. Role of weekly teriparatide administration in osseous union enhancement within six months after posterior or transforaminal lumbar interbody fusion for osteoporosisassociated lumbar degenerative disorders: a multicenter, prospective randomized study. J Bone Joint Surg Am. 2017;99(5):365-72.

\section{Publisher's Note}

Springer Nature remains neutral with regard to jurisdictional claims in published maps and institutional affiliations.
Ready to submit your research? Choose BMC and benefit from:

- fast, convenient online submission

- thorough peer review by experienced researchers in your field

- rapid publication on acceptance

- support for research data, including large and complex data types

- gold Open Access which fosters wider collaboration and increased citations

- maximum visibility for your research: over 100M website views per year

At BMC, research is always in progress.

Learn more biomedcentral.com/submissions 